\title{
Avoiding capital punishment
}

\author{
Justin Chakma, Eliot Forster \& Thomas E Hughes \\ In an industry with a lengthy product development timeline, capital efficiency is paramount. But successful \\ capital-efficient strategies require a different approach to thinking, working and fundraising.
}

$$
C_{d a b}^{a p d}
$$

apital efficiency is generally defined as doing more with less. The idea is particularly relevant now, but biotechs should always try to be efficient with their capital because it's often too late to tighten up the budget once resources become scarce.

In our view, capital efficiency is most closely related to strategies for spending and resourcing - in other words, achieving more with greater flexibility and precision, and using minimal resources. It means making it absolutely clear to your potential investors that you will carefully monitor your money (Box 1). And this is especially relevant to small biotechs for which acquisition is typically the ultimate objective.

Being a capital-efficient company (Box 2) has more to do with how you spend your money than with anything else. But it also deals with exploiting the many intrinsic, capital-efficient advantages associated with small biotechs. The first advantage is the lack of a costly 'legacy infrastructure,' comprising equipment or talent once needed but later underused due to strategy or scope changes. Lacking unneeded infrastructure means that companies can rent talent as needed and therefore access top-tier capabilities at a discounted cost. The second is the greater flexibility in R\&D spending, with a focus on getting the program to its key valueinflection point, typically proof of concept. And the third is the alignment of performance incentives and the company's mission-when compensation packages focus more on company equity, it helps attract collaborative team

Justin Chakma is an analyst at MaRS Innovation, Toronto, Ontario, Canada. Eliot Forster is president and CEO of Solace Pharmaceuticals, Boston, Massachusetts, USA. Thomas E. Hughes is president and CEO of Zafgen, Cambridge, Massachusetts, USA.

e-mail: justin.chakma@utoronto.ca,

eliotforster@solacepharma.comor

thughes@zafgen.com players who are focused on the company's goals. In the following article, we discuss how these advantages can be achieved in practice when setting up a life science venture.

\section{The right size, the right people}

Capital efficient organizations keep hiring lean, with most communication occurring through email and phone conferences to accommodate travel, coordinate efforts with vendors, and to facilitate after-hours work for teams that may be distributed across geographical regions. You need to ensure that your hires are comfortable with this sort of collaborative, real-time workflow. Without constant supervision, your employees will need to ask the right questions on their own and learn quickly. Make sure new hires have this ability.

Your employees also should plan on odd schedules, and the company should be up front about this. For example, one of us (T.E.H.) heads a team based in Cambridge, Massachusetts, that often holds night teleconferences with development colleagues in Australia as well as early morning calls with the drug discovery and formulation teams in the UK. Crying babies, washing machines and barking dogs are often the sound track to these meetings. It is a different way of life and a different way of doing business - most entrepreneurial people are fine with it, but any CEO of a startup should broach the topic with any potential new hire.

In general, you'll need employees who are capable of asking questions on their own. You'll want adaptable people who can learn quicklypeople who are comfortable both running projects and making their own coffee. In short, you need people who can network and who also have a level of autonomy and the ability to independently problem solve.

This raises the question: where does one find these sorts of hires? Personal contacts are important, but another way is to tap into the network of pharmaceutical advisors and contract research organizations (CROs). These individuals are already accustomed to the capital-efficient lifestyle and workflow; moreover, they are also solid networkers themselves and can help to drive further recruitment. Ask around and network; contacts, whether at CROs or elsewhere, are a good source of suggestions for potential employees.

What's more, working in virtual organizations across various time zones, as is often required to tap the best talent and maximize use of human capital, means that you are accountable for face time: as a founder or CEO, you'll need to travel and get out of the cave to communicate with your staff and your vendors. Phones will only take you so far. This means that although an organization needs to keep infrastructure costs to a minimum, a hub-with telephones, chairs and decent coffee-is also important for occasionally hosting partners and sharing ideas; it helps to build a sense of a team effort. Plan to meet with staff face to face and then communicate as the project plan dictates. For instance, when a company representative is required to attend a critical meeting in person, you make sure they get there-last year, one of us (T.E.H.) sent an employee to Australia for a 15-minute meeting. It was worth it.

\section{Order out}

Given that the majority of drug development costs occur during clinical trials, this area is ripe for conserving, and CROs often can produce results more cheaply than a small biotech ever could. To decide if your work is appropriate for outsourcing, determine if your project or set of experiments can be defined specifically (exploratory biology may not be well suited for a capital-efficient model, for example) and then look for available CROs, send out a request for proposals with project outcomes specified, and shortlist organizations based on those defined parameters. Finally, interview teams to assess the quality of their previous work and examine 
their background via reference checks, case studies and statistical models. It's also important to observe how the CRO interacts with your own team to determine whether it truly understands the business.

For the sake of expediency, it is often best to have relationships with CROs before you need them. One way to do this is to retain pharmaceutical advisors who have experience across a wide spectrum of skills, be it medical chemistry, toxicology or clinical trials. Those people and their networks should help you identify, and then get inside, the best shops quickly.

To help select a CRO, it's critical to understand what results you seek, so that your CRO partners and advisors truly understand what you're doing. Successful capital-efficient biotechs spend a great deal of time making sure that planning is correct and communicating those plans effectively, including specifying the output. You'll get only disaster if you walk into a $\mathrm{CRO}$ with a generic request for a clinical trial.

Besides, agreeing to precise specifications is a great way to minimize scope change (resulting in 'change orders'). About 25\% of CRO revenue comes from change orders, so proper due diligence and output specifications in a contract can save you big money. One final thing: when committing to a contract in a foreign country, consider hedging strategies in which you can secure an exchange rate (favorable or de-risked against adverse fluctuations) by buying in advance a portion of the currency needed to complete the deal.

There are many qualified CROs out there, but we have successfully worked with these: INC Research in Raleigh, North Carolina; ICON, based in Dublin, Ireland; Nucleus Network in Melbourne, Australia; Trident Clinical Research in Port Adelaide, Australia; and Q-Pharm in Queensland, Australia.

\section{Before man}

Most early-stage biotechs are first created as virtual operations in academic labs, so there is a temptation to outsource preclinical work to the academic labs instead of to CROs. This makes sense, and some universities now

\section{Box 1 Pitching for capital efficiency}

For better or worse, every CEO is going to boast about his or her company being capital efficient. But how do you truly show that your biotech's capital-efficient model is real?

Proof of capital efficiency comes from your full-time employee count and financial statements. When investors ask about your financing history, point to your, say, six or fewer employees and mention a specific achievement, such as hitting all your milestones with this small group. You'll also want to show investors your financial statements and business plan, then describe what you have delivered and what you intend on delivering. If your past or future infrastructure to operational spending ratio is greater than $1: 1$, you have a problem. Your $\mathrm{COO}$ should determine whether your infrastructure cost is less than your operational spending before releasing any money to spend on, for example, a new hire. One test to apply would be to ask what your fixed costs (including payroll) represent as a fraction of your total running cost and what it would cost in time and dollars to shut down the enterprise.

The bottom line in the biotech world is: 'the more you hire, the more you fire.' It's best to avoid that by being capital efficient from the very beginning and making that clear to your venture capitalists. It also helps to articulate a pathological hatred of large infrastructure. Also, be honest about your expenses and show that you've done due diligence to reduce them. This means determining where and when it is appropriate to be capital efficient. Determine the vendors in your arena, get quotes and have each expense item accounted for with an appropriate source for your business plan. You should lay out multiple scenarios for clinical trials and present their true and complete costs to give the full scope of possibilities. You have to show venture capitalists that you know what it means to be capital efficient, not just tell them you know.

If possible, it's best to approach venture capital firms that truly understand the capitalefficient model. These are the firms that build a portfolio project by project and take a 'shots on goal' approach, where the risk of each program is overseen at the fund level rather than the firm level. The management teams of venture capital firms are mobile and are aligned to kill bad projects.

Some venture capitalist firms that follow this process are Atlas Ventures, based in Waltham, Massachusetts, and Scale Venture Partners in Foster City, California, both of which often integrate management teams into their network and involve them as advisors across the breadth of the portfolio; InterWest in Menlo Park, California; Polaris in Waltham; New Enterprise Associates, based in Menlo Park; Sofinnova in Paris; New Leaf Ventures in Menlo Park; and Third Rock Ventures in Boston.

support laboratory facilities that can be accessed by external groups at a fair price. In fact, Zafgen in Cambridge, Massachusetts, has tapped into several such core facilities to support studies requiring gene expression analysis and specialized clinical chemistry readouts.

That said, in our experience, it's rare that an academic lab can offer the support and terms provided by specialist, professional vendors. Universities are notorious for taking a long time to negotiate contracts, and experiments can be held up for 6-12 months due to paperwork at technology transfer offices. Issues can arise around publication, inability to draw contracts, turnover of tech transfer staff and intellectual property concerns.

Also, universities often are not adept at performing studies that require repetition, as is frequently needed in drug discovery. (In contrast, good CROs repeat the same task reliably time after time.) It's difficult to know when to use a university, but the partnership usually works best when both the academic motivation for conducting new research and the company's motivation for drug discovery progress align. In these cases, companies can access years of academic experience. Capital-efficient biotechs must weigh the pros of experience and a low cost with the cons of potential delays and the different culture of academic labs.

But there are other parameters to consider beyond time and cost. Academic collaborators often are best equipped and best able to help answer the tough 'how' questions: How does manipulation of this drug target impact the disease state at the whole animal, tissue, cell or pathway level? How useful is this approach at different stages of the disease process? Or, How does this treatment stack up against standard of care or competing emerging agents? Professional contract organizations are better at answering the 'what' questions: What is the potency of this molecule? What is the distribution of this molecule in different tissues? Or, What is the impact of treatment on a range of standardized endpoints?

Your decision about preclinical work should also consider which approach will provide the greatest assurance to big pharma decision makers. In this regard, professional organizations might provide the greatest comfort when clearly documented results are needed concerning the mechanics of the program (drug exposure and metabolism, safety and efficacy, and so on). Academic collaborations help provide comfort on the hairier question of whether the therapeutics strategy is attractive from an investment standpoint. Publications from trusted investigators can go a long way with pharma and can reduce their stress when deciding to go with an expensive and risky in-licensing deal. 
We recommend these CROs for preclinical work: Galapagos in Mechelen, Belgium; Evotec, based in Hamburg, Germany; GVK Biosciences Private in Hyderabad, India; Cerep in Paris, France; and RenaSci in Nottingham, UK.

\section{Making the call}

As hinted in the previous section, managers must ensure the research is sufficiently focused. Can you define a sequential step of experiments that will signal a 'go' or 'no go' for your project? To do this, you must establish priorities: conduct due diligence to eliminate risk factors such as intellectual property, then assess the accessibility of starting materials and so on. This will help you not only reduce unexpected or unnecessary deviations from the business strategy but also identify questions that may not be immediately available and determine potentially rate-limiting activities.

In the experience of two of us (T.E.H. and E.F.), the rate-limiting activities are set by identifying the most important piece of data needed for a project. The firms then plan out the entire sequence of activities that will produce that piece of data. It becomes a priority, with other components being run more quickly or more slowly around it. Setting priorities in this way prevents a company from having many projects going on at once, which can lead to an inability to control third parties, resulting in cost and time overruns. Keep an eye on what's important, and change it only in rare circumstances.

Part of prioritizing is weighing the urgency of the activity versus a willingness to pay for it, so you should be able to explicitly define the conditions in which you will outsource. Is the task defined? Is the task time sensitive? Being able to answer these questions easily depends on having conducted sufficient due diligence and having a hard strategy. For instance, always trying to negotiate a lower price may bring added costs by increasing the time it takes to complete the project. Is speed or cost more important to the health of your company? It's critical to understand how your different pieces fit together.

A project management program, such as web-based software like Tenrox or Microsoft Project, can help you track outstanding financial and project controls, as well as give you a database of contracts and collaborations. Gantt charts (horizontal bar charts that represent the duration of tasks set against the progression of time for resource allocation, annotated with key decision points and criteria) are helpful, as well as being useful for identifying responsibilities.

Finally, it's likely in your small firm that the decision-making group is only the executive team and the board members. Use this as an advantage and avoid creating too many committees or firm processes. Think each

\section{Box 2 Defining capital efficiency}

Capital expenditures (CapEx) are expenditures that create future benefits. Examples include the development of infrastructure and acquisition of equipment that has a long, useful life span. These types of expenditures obtain entities that will usually last five years or more and are depreciated or amortized accordingly. If you are working in an organization with relatively short-term objectives, such as a venture capital-funded biotech, or a biotech in which there are changing priorities or efforts, then you should minimize your CapEx and manage the activities through operational expenditures (OpEx). Keeping a low CapEx to OpEx ratio is one way of being capital efficient.

Capital efficiency should also be applied during cash-flush times. Remember that raising incrementally larger amounts of capital delivers less attractive returns for your venture capitalists. Capital-efficient companies also tend to have fewer shareholders and simpler governance in the board room, both of which can mean a more collaborative and intimate investor involvement. problem through but make decisions firmly and quickly.

\section{Get organized}

With the continuing globalization of biotech, it is important to identify and leverage expertise in multiple regions. But this task is not simple. Understanding where and when you intend to use a region for a certain task from the outset is critical in shaping how you organize your biotech.

Two of us (T.E.H. and E.F.) have direct experience trying to complete biology work in emerging markets, such as India, but have had little success (so far). Mainly that's because outsourcing of biological work remains primarily the province of the US and Europe. However, chemistry, especially routine chemical synthesis, is conducted successfully and cost effectively in India. For clinical trials, the location of the CRO is not as important as its international reach, because increasingly it's undesirable to conduct phase 2 and 3 trials in just one country, due to competition for certain patient populations among other reasons.

To leverage the global nature of contract research work, Zafgen and Solace Pharmaceuticals, based in Boston, Massachusetts, have taken different approaches. Solace set up facilities in both Cambridge, Massachusetts, and Canterbury, UK, to allow the company to work together with CROs from India and China, as well as with the West Coast of the US, in a single (long) working day. Zafgen, on the other hand, opted for a fully integrated model with only a small number of CROs supporting its drug discovery program. By using a 'full-stop shop' with molecular modeling, chemistry, assay work and optimization, Zafgen employs a simple organizational structure and has reduced its dependence on building a supply and data management structure. The logistics for sending samples and managing data between CROs are complicated and can lead to delays and errors if not carefully managed.

Which organizational structure you opt for will depend on your stage of development and your therapeutic area. For preclinical work, the headquarters of your company or vendor is critical for optimizing global workflow. Fullstop shops are more amenable to optimizing new compounds for established targets rather than exploiting new drug targets. For clinical development work, most capital-efficient companies opt to go with a single global CRO, so the diversification of location matters less. But, clinical trials for niche diseases are more likely to be sourced to specialized CROs, meaning managers need to plan and adapt their organizations accordingly.

\section{Conclusions}

Executing a capital-efficient model in biotech is challenging but worthy of consideration. In the past, big pharma may have valued infrastructure in biotechs, but it is moving in the opposite direction today. These days, a slimmer biotech is more attractive.

Individuals in a capital-efficient organization need to be able to translate complex scientific needs into concise and clear project specifications for third-party CROs and advisors. The next cadre of successful bioentrepreneurs will need to be good scientists and have the wherewithal to mold their vision into great work plans for others. Ultimately, of course, it is results that matter. Biotech projects that both advance new treatments and release investor value will lead the way. Those types of firms are best formed through capital efficiency.
To discuss the contents of this article, join the Bioentrepreneur forum on Nature Network: http://network.nature.com/groups/bioentrepreneur/forum/topics 